\title{
A MATRIZ ENERGÉTICA BAIANA E O POTENCIAL DE APROVEITAMENTO SOLAR E EÓLICO NA GERAÇÃO DE ENERGIA ELÉTRICA NO ESTADO DA BAHIA
}

\section{THE ENERGY MATRIX IN BAHIA AND THE POTENTIAL OF SOLAR AND WIND ENERGY IN THE GENERATION OF ELECTRICITY IN THE BAHIA STATE}

Thiago Figueiredo de Oliveira

Engenheiro Ambiental e Sanitarista, Pós-graduando em Engenharia de Segurança do Trabalho. (thiago.ambiental@yahoo.com.br)

Karina Barbosa de Souza

Engenheira Ambiental e Sanitarista. (karibsouza@gmail.com)

João Florêncio Rocha Neto

Engenheiro Ambiental e Sanitarista. (joaof.rocha@yahoo.com.br)

Elizabeth da Rocha Couto

Doutora em Química/UFBA. Centro Universitário Jorge Amado. (coutore@hotmail.com)

\section{Resumo}

O presente estudo possui como objetivo norteador a avaliação do potencial de aproveitamento solar e eólico para a geração de energia elétrica no estado da Bahia, apresentando vantagens, desvantagens e um levantamento da estimativa de quanto poderia se acrescentar na composição da matriz energética estadual. Com o decorrer da pesquisa, foi observado um enorme potencial de aproveitamento solar e eólico para geração de eletricidade no Estado, no qual, atualmente, concentram-se investimentos significativos do setor, em que a região centro-oeste foi a que se apresentou como a mais promissora. Em contrapartida, ainda existem barreiras ao desevolvimento e disseminação de tais tecnologias, como problemas relacionados à falta de linhas de transmissão. Como base metodológica, foi realizada pesquisa e coleta de dados preferenciais em agências, associações e empresas atuantes no setor de energia, a exemplo de Agência Nacional de Energia Elétrica e Associações Brasileiras de Energia Eólica e de Energia Solar, visando-se sempre uma maior confiabilidade nas informações.

Palavras-chave: Usina solar fotovoltaica, usina eólica, matriz energética.

\section{Abstract}

The present study has as a guiding objective the evaluation of the potential of solar and wind exploitation for the generation of electric energy in the state of Bahia, presenting their pros, cons and a survey of the estimation of how much they could add in the composition of the state energy matrix. Throughout the research, there was an enormous potential for solar and wind power generation for the generation of electricity in the state of Bahia, in which, currently, significant investments are concentrated in the sector, where the central-western region of the state was the most promising. On the other hand, there are still barriers to the development and dissemination of such technologies, such as problems related to the lack of transmission lines. As a methodological basis, research and collection of preferential data was carried out in agencies, associations and companies operating in the energy sector, such as the National Electric Energy Agency, Brazilian Wind Energy Associations and Solar Energy, always aiming for greater reliability Information.

Keywords: Solar photovoltaic power plant, wind farm, energy matrix.

\section{INTRODUÇÃO}

Em um contexto atual de intensos e constantes debates envolvendo as mudanças climáticas e a maneira como elas interferem na forma e na qualidade de vida humana, tecnologias que reduzem ou não promovem impactos ao meio ambiente estão cada vez mais em destaque e no centro das atenções da sociedade atual.

Seguindo essa linha de pensamento, a disseminação de fontes renováveis de energia, 
principalmente aquelas relacionadas ao uso da força motriz dos ventos e da luz do sol, vem e tende a acontecer naturalmente dentro do setor energético mundial, em detrimento da utilização daquelas que são mais emissoras de poluentes atmosféricos. Isso é corroborado pela proposição contida no Protocolo de Kyoto, tratado internacional criado no ano de 1997 e que entrou em vigência a partir de fevereiro de 2005, o qual define metas de redução na emissão de gases de efeito estufa (GEE) à atmosfera, principalmente por parte dos países considerados mais desenvolvidos, como forma de reduzir os impactos climáticos negativos provocados pelo aquecimento global (BRASIL, 2016).

No Brasil, de acordo com a Agência Nacional de Energia Elétrica, a geração de energia a partir das usinas hidrelétricas ainda é predominante, representando cerca de $61,3 \%$ da capacidade instalada em operação no país, seguida pelas termelétricas (gás natural, carvão mineral, combustíveis fósseis, biomassa e nuclear), que podem ser altamente poluidoras, representando $28 \%$ (ANEEL, 2016). No entanto, verifica-se que o país possui uma excelente capacidade para aproveitar a energia que é produzida por meio de outras fontes renováveis, especialmente eólica e solar, até mesmo como forma complementar na geração.

De forma breve, pode-se dizer que para 0 funcionamento de um sistema de energia solar é essencial que haja a incidência da radiação do sol em uma determinada região, com a consequente captação e posterior conversão da energia irradiada em energia elétrica, através de placas fotovoltaicas. Já para o sistema de energia eólica, proveniente da ação dos ventos, é necessário que se tenha a movimentação do ar presente na atmosfera e que possibilite 0 movimento suficiente do aerogerador ou turbina eólica, que é responsável por converter a energia cinética dos ventos em energia elétrica, através de um gerador (ALDABÓ, 2002).

Visto que a quantidade de energia gerada depende essencialmente da capacidade de incidência e da frequência com que ocorrem tais fontes em uma determinada região, nota-se que o Brasil se torna um país privilegiado por possuir condições climáticas propícias ao longo de seu território, especialmente nas regiões Norte e Nordeste, responsáveis por apresentar altas taxas de irradiação solar e velocidade dos ventos.
Diante desse contexto, este estudo tem como objetivo norteador avaliar o potencial de utilização da força motriz dos ventos e da luz do sol (fontes renováveis de energia) para a geração de energia elétrica na Bahia, apresentando os atuais percentuais de participação na composição da matriz energética do Estado e identificando os principais impactos ambientais advindos de sua instalação. O estudo se justifica, essencialmente, pelos argumentos acima apresentados, mas também devido à necessidade de esclarecimentos à população acerca dos atuais problemas energéticos enfrentados pelo país, e que ainda demandam possíveis acréscimos nas tarifas praticadas e em possíveis prejuízos à economia brasileira.

\section{FUNDAMENTAÇÃO TEÓRICA}

\subsection{Energia Eólica}

\subsubsection{Método de funcionamento}

A primeira turbina eólica comercial ligada à rede elétrica pública foi instalada em 1976, na Dinamarca. No Brasil, a determinação do potencial eólico e a instalação das primeiras turbinas eólicas foram possíveis a partir dos resultados de medições realizadas por meio dos primeiros anemógrafos computadorizados e sensores especiais para energia eólica instalados no Ceará e Fernando de Noronha (PE), no início dos anos 1990 (ANEEL, 2008).

De acordo com Leite et al. (2006), uma turbina eólica é construída por uma série de componentes, que são responsáveis pela produção de energia elétrica, sendo divididos em três etapas: captação da energia cinética contida no vento, conversão da energia cinética em energia mecânica e transformação da energia mecânica em energia elétrica pelo gerador elétrico. Assim, para que isso ocorra, existem dois tipos básicos de rotores aerogeradores eólicos de eixo vertical e de eixo horizontal -, que diferem conforme rendimento aerodinâmico, eficiência, esforços mecânicos, velocidade do vento, sendo esta a que apresenta maior eficiência produtiva, entre outros.

No Brasil e no mundo, estudos indicam que os aerogeradores mais utilizados são aqueles com eixo do tipo horizontal, nos quais se podem encontrar rotores constituídos por uma, duas, três ou múltiplas pás, sendo os rotores de três pás os mais usados atualmente em usinas eólicas 
destinadas à geração de energia elétrica em grande escala. As pás do rotor são as responsáveis pela captura da energia dos ventos e por sua posterior conversão em energia rotacional no eixo, que possui a função de transferir essa energia rotacional até o gerador, a ser utilizada para geração de energia elétrica através de processos eletromagnéticos, conforme demonstrado na Figura 1.

\section{Figura 1: Etapas de funcionamento de um aerogerador}

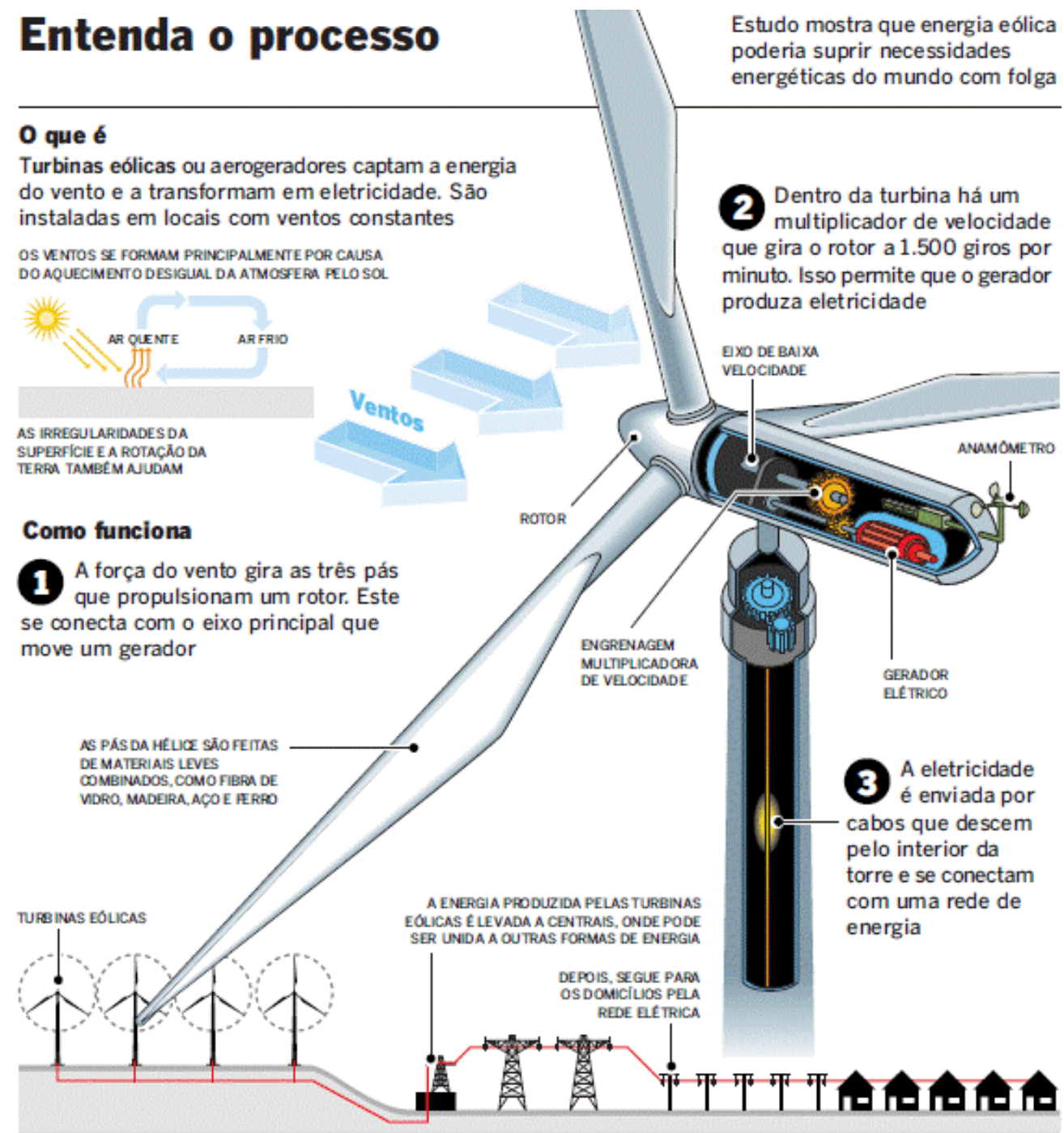

Fonte: Evolução Energia Eólica (2016).

Entretanto, uma ressalva que se faz e que talvez seja um grande empecilho encontrado nestes equipamentos é a necessidade frequente de medição da velocidade dos ventos, visto que, no caso de ser baixa, talvez não seja vantajosa a manutenção do seu uso e funcionamento. Por isso, é que se fazem necessários estudos para instalação de parques eólicos em áreas nas quais a velocidade dos ventos seja adequada $e$ constante.
Além disso, para a formação, movimentação e velocidade dos ventos, há diversos fatores influenciadores a serem destacados, tais como localidade, corpos d'água, relevo e a própria vegetação existente no local. Tais fatores estão intimamente ligados à capacidade de um aerogerador capturar a energia cinética contida nos ventos e permitir a transformação em energia mecânica e elétrica. 


\subsubsection{Impactos ambientais e sociais}

Os impactos ambientais e sociais provenientes da instalação de usinas eólicas em uma determinada localização podem ocorrer tanto na fase de construção, quanto na permanência do empreendimento, sendo alguns destes brevemente descritos a seguir.

Os principais impactos ambientais listados podem afetar diretamente a flora e a fauna local e variam de acordo com sua região e/ou zona. $\mathrm{Na}$ fase inicial do projeto, as alterações mais relevantes são a supressão da vegetação, remoção de terra, compactação do terreno por máquinas, desmatamento, além da promoção, supressão e fragmentação local dos ecossistemas relacionados. Neste contexto, Meireles (2009 apud FILHO; AZEVEVEDO, 2013, p.4) destaca que estudos anteriormente realizados demonstram que tais atividades frequentemente se encontram em áreas componentes de sistemas de preservação permanente e que, assim, a extinção de setores fixados pela vegetação, bem como a supressão de ecossistemas antes ocupados por fauna e flora específicas seriam as possíveis consequências negativas que podem acontecer.

Após a efetivação da usina e o seu funcionamento, algumas preocupações adicionais com o meio ambiente começam a surgir. A grande questão relacionada à fauna do local é o impacto possível de vir a ocorrer com as aves, que pode ser direto (animais colidem com grandes estruturas, como torres de alta tensão ou turbinas eólicas) e/ou indireto (alterações nos padrões de migração devido à perturbação causada, com consequente deslocamento ou exclusão das aves), além de riscos aos demais animais habitantes da região ou que a possuem como rota de convivência.

Além da fauna, o meio físico também sofre alguns abalos após a implantação do empreendimento. Os aerogeradores, com alturas das torres superiores a $100 \mathrm{~m}$ e comprimento das pás acima de $30 \mathrm{~m}$, certamente, causam grandes impactos visuais para a região. Outro impacto que pode ser considerado é o sonoro, principalmente aquele decorrente das turbinas eólicas, as quais produzem ruídos provenientes dos mecanismos de engrenagens e pela passagem do ar nas pás. Há outras perturbações, como a interferência eletromagnética em aparelhos de transmissões e compactações do solo. Porém, tais impactos, além de passíveis de serem significativamente minimizados e até mesmo eliminados, podem se tornar desprezíveis quando considerados os benefícios ambientais advindos da utilização das usinas eólicas em comparação a outras fontes de geração de energia existentes e ainda usuais.

Tendo o vento como sua fonte principal, os parques eólicos possuem um recurso renovável e teoricamente inesgotável. Além disso, esta fonte emite pequena ou mesmo nenhuma quantidade de gases poluidores e as turbinas necessitam de pouca manutenção. Jacobson et al. (2008 apud SALINO, 2011, p.32) confirmam que a energia gerada pelos parques eólicos é considerada de baixa emissão, visto que há pouca ou nenhuma emissão de gases poluentes, como material particulado, óxidos de enxofre ou nitrogênio, normalmente derivados da combustão de combustíveis fósseis e prejudiciais à saúde humana.

No meio social, os parques eólicos podem gerar, de forma oportuna, crescimento e valorização de determinadas regiões que até então eram zonas desfavorecidas, uma vez que normalmente são instalados em zonas rurais menos povoadas, gerando emprego e renda para a população local, além de possuírem compatibilidade com a utilização do terreno para outras finalidades, como agricultura e também pecuária. Isto ocorre porque os impactos ocasionados ao solo, apesar de existentes, normalmente são admitidos como baixos, não interferindo, assim, em outras práticas de utilização do terreno, já que a ocupação de uma turbina eólica está restrita à pequena área que contém sua base de concreto para sustentação.

Segundo a Associação Europeia de Energia Eólica - EWEA (2000 apud TERCIOTE, 2002, p. 5 ), cerca de $99 \%$ da área na qual uma usina eólica típica está localizada ficam disponíveis fisicamente à utilização da terra, visto que, embora tenham aproximadamente 10 metros de diâmetro, as fundações dos aerogeradores normalmente estão enterradas, fato que permite às atividades agrícolas e/ou pecuárias serem mantidas até próximas à base da torre.

Ademais, e analisando os problemas atuais em decorrência do consumo da água, considerada um bem cada vez mais escasso, torna-se importante ressaltar que a produção de energia por meio da força motriz dos ventos não demanda consumo de $\mathrm{H}_{2} \mathrm{O}$. Suas turbinas aerogeradores podem ser utilizadas em conexão com redes e também em locais isolados, não 
necessitando de linhas de transmissão para alimentar determinadas regiões. Para efeito de comparação, a cada $100 \mathrm{MW}$ produzidos em parques eólicos brasileiros, são economizados 40 $\mathrm{m}^{3} \mathrm{~s}$ de água na cascata do rio São Francisco (QUAGLIA, 2010).

\subsection{Energia Solar Fotovoltaica}

\subsubsection{Método de funcionamento}

A energia solar fotovoltaica é obtida através da conversão direta da luz solar em eletricidade, denominada de efeito fotovoltaico, e é realizada por meio de dispositivos fotovoltaicos (FV). Tal efeito foi verificado pela primeira vez pelo físico francês Edmond Becquerel, em 1839, e considerado como o aparecimento de uma diferença de potencial nos extremos de uma estrutura de material semicondutor, produzida pela absorção da luz, ou seja, no momento da interação da radiação solar com o material semicondutor ocorre a liberação e movimentação de elétrons por este material, gerando-se essa diferença de potencial (CRESESB, 2004).

Portanto, são nas células solares que ocorre o efeito fotovoltaico, sendo elas as principais responsáveis pelo funcionamento dos sistemas fotovoltaicos. Os materiais semicondutores mencionados são elementos fundamentais e mais adequados para a utilização nestes dispositivos, por apresentarem uma boa estrutura atômica cristalina e condutividade elétrica. Dentre os existentes, o silício é o mais utilizado, devido à sua abundância.

Estes sistemas fotovoltaicos, além de possibilitarem a conversão da luz do Sol em energia elétrica, podem contribuir, de forma significativa, para a geração da energia elétrica que é consumida nos grandes centros urbanos (SANTOS et al., 2008). Segundo a NBR 11704 (ASSOCIAÇÃO BRASILEIRA DE NORMAS TÉCNICAS, 2008, p. 2), tais sistemas estão divididos em dois tipos, quais sejam: os isolados e os conectados à rede elétrica (Figura 2).

Como se pode observar através do esquema acima, os sistemas conectados à rede são compostos basicamente por painel fotovoltaico, inversor e medidor de energia bilateral (que contabiliza a energia que é gerada pelo sistema e a que é recebida pela rede), ou simplesmente um gerador FV e o inversor. Neste tipo de sistema, não se tem um dispositivo de armazenamento de energia (bateria), função que está atribuída praticamente à própria rede elétrica da concessionária, pois é esta última que terá o papel de suprir as necessidades do consumidor conforme a demanda. Ou seja, quando a energia gerada é maior que a demanda da residência, por exemplo, a rede se encarrega de absorver o excedente e transmitir para outros pontos de consumo. No caso contrário, a concessionária deverá suprir o consumidor.

Já para o sistema isolado, tem-se a presença de um painel fotovoltaico (gerador FV) controlador de carga, baterias e inversor. Neste caso, a energia que é gerada será armazenada nas baterias, passando antes por um controlador de carga, que evita a carga excessiva ou reduzida numa bateria, aumentando a sua vida útil. Logo, essa energia poderá ser utilizada instantaneamente em uma corrente contínua, ou transmitida para o inversor que a transforma de corrente contínua para a alternada. Para este tipo de sistema, o uso de baterias é essencial para seu funcionamento, sendo de fundamental importância a elaboração de um projeto que permita a sua autonomia e que garanta o fornecimento de energia.

Em uma comparação simples, observa-se que o sistema isolado apresenta algumas desvantagens em relação ao sistema ligado à rede, especialmente quando se trata das baterias (vida útil), manutenção e produtividade, responsáveis pelo custo de implantação e possível adoção das tecnologias voltadas para a energia solar em determinadas regiões.

\subsubsection{Impactos ambientais e sociais}

Assim como acontece nos parques eólicos, as usinas solares também podem acarretar impactos negativos ao meio ambiente desde a fase de implantação do projeto; dentre estes, a aceleração dos processos erosivos, alteração pedológica local e, através da necessidade de preparação do terreno, algumas perdas relacionadas à flora. Ainda durante a implantação do projeto, outras pequenas alterações podem ocorrer relacionadas à fauna local, como o afugentamento em decorrência das mudanças ao seu habitat natural, além das possíveis queimaduras, em aves, por exemplo, por conta dos reflexos dos raios solares nos painéis fotovoltaicos.

Iniciado o processo de operação da usina, alguns impactos podem vir a acontecer, como a alteração da paisagem local, uma vez que 
grandes placas solares são necessárias para o funcionamento das usinas, bem como outros materiais trazidos para a região. Assim como ocorre nos parques eólicos, os parques solares fotovoltaicos necessitam de grandes áreas para sua implantação, principalmente em regiões rurais. Contudo, diferentemente dos primeiros, tais áreas ficam impossibilitadas de uso para outros fins.

Além disto, há outros impactos a serem considerados, porém, facilmente desprezados, visto que os transtornos que acarretariam ao meio ambiente são mínimos e de fácil controle. Vale ressaltar ainda a necessidade de realização do correto descarte das baterias que, ao final da vida útil, se tornam resíduos, assim como atenção a outros materiais tóxicos que tenham sido gerados como produto final.

No mais, como observado nos parques eólicos, na parte dos impactos sociais associados às usinas solares, o efeito não seria diferente, pois o projeto prevê a contratação de quantidades elevadas de mão de obra, principalmente durante a fase de pré-operação/construção da unidade. Além disso, haveria possível valorização ou desvalorização imobiliária no entorno do empreendimento instalado.

\section{Figura 2: Esquema dos sistemas fotovoltaicos conectados à rede e isolados}

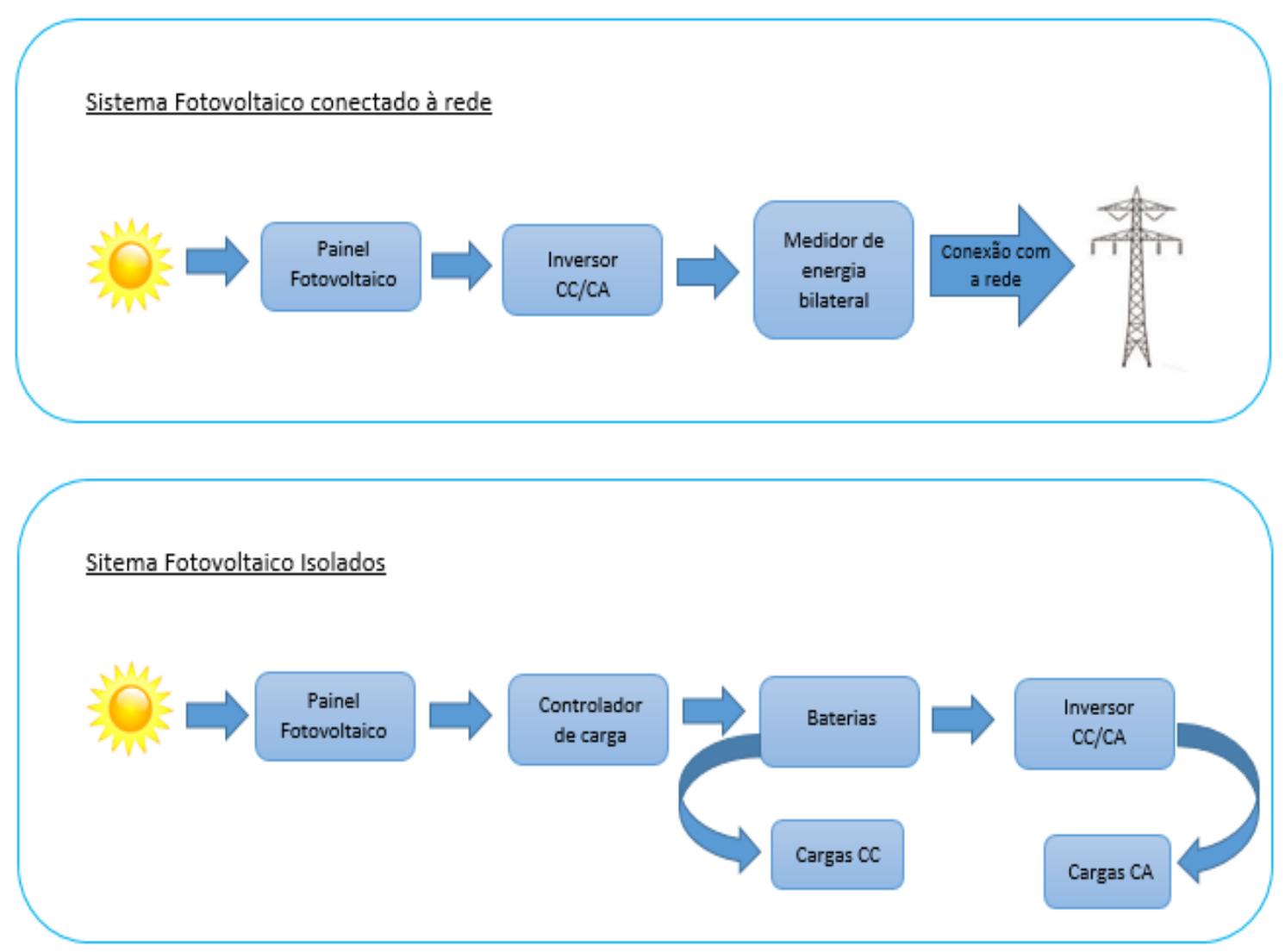

Fonte: Adaptada de Miranda e Machado (2014).

\section{METODOLOGIA}

Para o desenvolvimento do estudo e a consequente elaboração deste artigo, buscou-se, inicialmente, um processo de revisão bibliográfica da literatura, através do levantamento de normas, artigos, dissertações e revistas anteriormente publicadas sobre o tema em foco, com intuito de se trazer uma maior fundamentação teórica para o presente trabalho.

Também foram realizadas coletas de dados e informações disponibilizadas na rede mundial de computadores (Internet). Dentre as pesquisas realizadas, podem-se destacar os dados obtidos do Ministério de Minas e Energia (MME), da Empresa de Pesquisa Energética (EPE), da Agência Nacional de Energia Elétrica (ANEEL), 
das Centrais Elétricas Brasileiras S.A. (ELETROBRÁS), da Associação Brasileira de Energia Eólica (ABEEólica) e da Associação Brasileira de Energia Solar (ABENS), além de outras empresas e/ou organizações do setor.

Posterior a esta etapa e após o levantamento dos impactos ambientais advindos da instalação de parques eólicos e usinas solares de energia, foi realizada uma análise, superficial, mas embasada criticamente, do potencial que 0 estado da Bahia possui para alavancar a sua geração de energia elétrica por meio da utilização de tais fontes renováveis. Por fim, efetuou-se organização dos dados e das informações reunidos ao longo do estudo, de forma que fosse possível obtenção de posicionamento sobre 0 potencial de aproveitamento solar e eólico na geração de energia elétrica em território baiano.

\section{AVALIAÇÃO PRIMÁRIA DO POTENCIAL DE APROVEITAMENTO SOLAR E EÓLICO NA GERAÇÃO DE ENERGIA ELÉTRICA NO ESTADO DA BAHIA}

Com o constante aumento do consumo de energia elétrica, a matriz energética mundial vem ampliando a sua diversidade de forma mais intensa ao longo dos últimos anos. No entanto, essa variabilidade de fontes de energia depende essencialmente daquilo que uma determinada região tem a oferecer e, nesse caso, alguns fatores, como a disponibilidade de recursos, interesses comerciais, domínio de tecnologias e a preservação do meio ambiente, levaram os países a diferentes escolhas para a composição de suas matrizes (FARIAS; SELLITTO, 2011).

No caso do Brasil, o país conta com diversas usinas hidrelétricas espalhadas em seu território nacional, sendo um contraste em relação a outras nações. De fato, é possível reconhecer o motivo pelo qual o Brasil optou por tais fontes, especialmente quando se tem o conhecimento da existência de seus grandes rios e chuvas tropicais abundantes, que alimentam os mesmos, além de ser uma forma de geração de energia mais barata operacionalmente. Dessa forma, as usinas hidrelétricas são as responsáveis pelo maior percentual da composição da matriz energética nacional, correspondendo a cerca de $61,3 \%$ da capacidade instalada total em operação no país, conforme pode ser observado na Figura 3.

Figura 3: Atual composição da matriz elétrica nacional

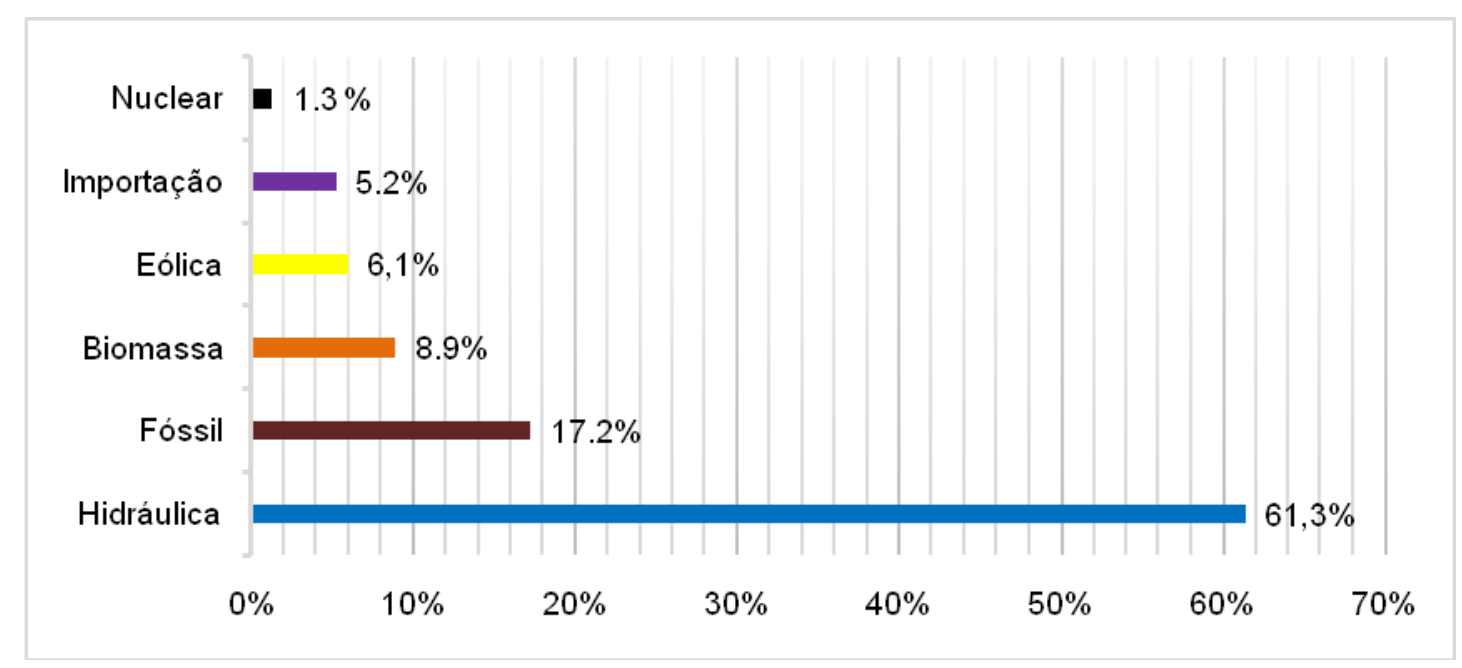

Fonte: Adaptada de ANEEL (2016).

Ao analisar a figura anterior, nota-se que o percentual de participação das fontes provenientes de energia solar ainda é insignificante na geração de energia elétrica total do país, tanto que nem sequer aparece na imagem gráfica retratada acima, devido ao baixo percentual gerado. Atualmente, existem 42 usinas solares já estabelecidas no país, com capacidade instalada total de $27.008 \mathrm{~kW}$, o que representa apenas $0,02 \%$ da energia gerada nacionalmente. 
Dentro deste cenário, a região Nordeste é a que apresenta a maior probabilidade de desenvolvimento para o setor energético no país, principalmente se relacionada à incidência de radiação solar extremamente favorável (ATLAS SOLARIMÉTRICO DO BRASIL, 2000), adicionada ao fato de que o vento brasileiro está predominantemente localizado na parte setentrional desta região (BARIFOUSE; SCHREIBER, 2015).

No estado da Bahia, a geração de energia por meio do aproveitamento da força da água também é bastante representativa. Do total de 207 empreendimentos atualmente em operação no Estado (que totalizam uma geração de 9.550,627 MW de potência), 32 estão associados a Centrais Geradoras Hidrelétricas (CGE), Pequenas Centrais Hidrelétricas ( $\mathrm{PCH}$ ) e/ou Usinas Hidrelétricas (UHE), mas que respondem por cerca de $60 \%$ da quantidade de energia gerada, enquanto que as termelétricas possuem 105 empreendimentos em operação, contribuindo com aproximadamente $22 \%$ da energia gerada. Além disso, deve ser ressaltado que existe um total de 68 Centrais Geradoras Eólicas (EOL) em operação no território baiano, representando cerca de $18 \%$ da energia gerada, conforme dados de outubro de 2016 (ANEEL, 2016) (Figura 4). Já o percentual relacionado às Centrais Geradoras Solares Fotovoltaicas (UFV), atualmente, é desprezível, respondendo por cerca de 0,03\%.

Figura 4: Atual composição da matriz elétrica baiana

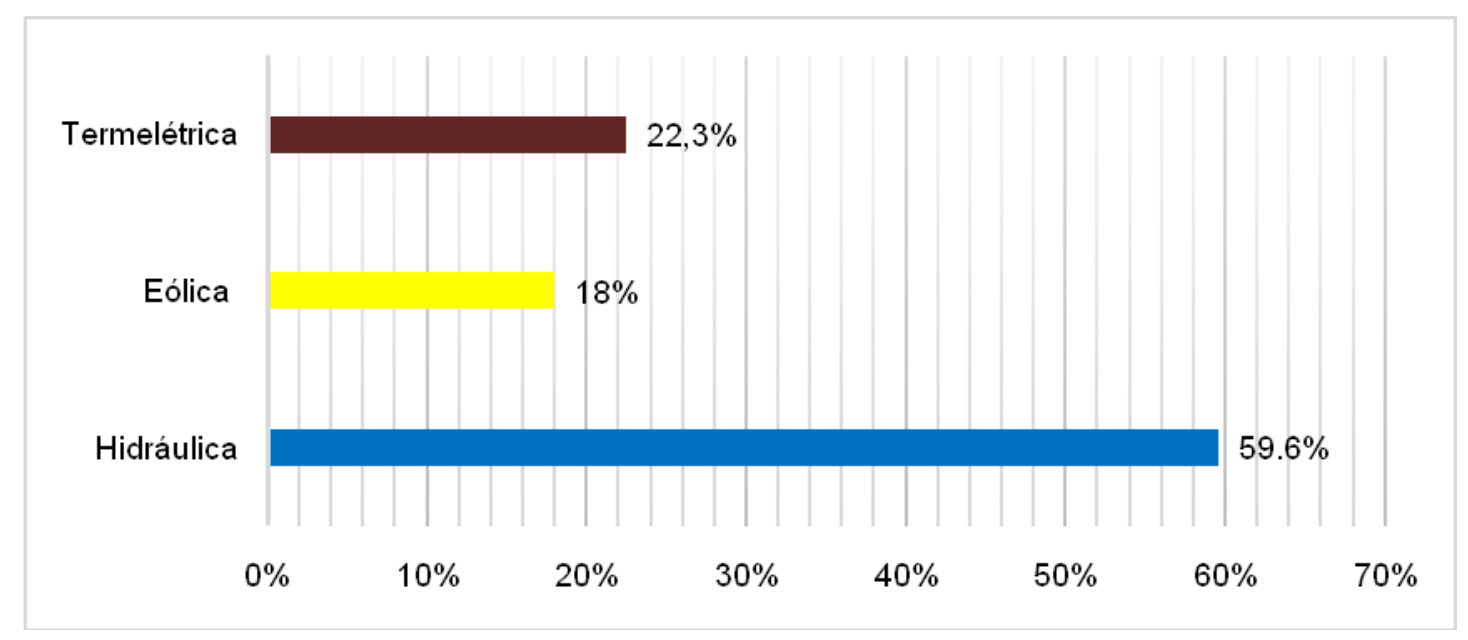

Fonte: Adaptada de ANEEL (2016).

Contudo, tal cenário, impreterivelmente, tende a mudar, pois estão em fase de construção 46 Centrais Geradoras Eólicas em todo o Estado, com potência prevista de $901,5 \mathrm{MW}$, assim como outros 118 empreendimentos projetados. Além disso, existem três empreendimentos em construção de Centrais Geradoras Solares Fotovoltaicas, com potência prevista de $84,0 \mathrm{MW}$, e outros 29 projetos previstos a serem construídos no Estado.

Para que tais fontes de geração de energia possam ser consideradas e possivelmente construídas em uma dada região, torna-se necessária a avaliação de alguns fatores. Segundo o Laboratório Nacional de Energia Renovável - NREL (2010 apud BRASIL, 2014, p.14), em nível de recurso, se consideram, basicamente, a quantidade, o horizonte de disponibilidade e a localização geográfica de cada fonte, assim como seu respectivo conteúdo energético; em nível técnico, incorporam-se as limitações técnicas e de uso do solo (nele são examinadas as oportunidades de conversão do recurso em formas úteis, através de tecnologias específicas); no nível econômico, por sua vez, agregam-se o custo da tecnologia e outros fatores econômicos. Finalmente, são incluídas considerações de mercado, como demanda, oferta, regulação, incentivos, investimentos, entre outros.

No caso das usinas solares fotovoltaicas, para que estas obtenham seu efetivo potencial, alguns fatores adicionais devem ser analisados. O índice de radiação solar da região é o ponto 
principal que determinará grande parte da produção e, para que esse índice seja estabelecido, deve ser levada em consideração a composição atmosférica, como nebulosidade e umidade relativa do ar. Já para a construção dos parques eólicos, deve-se ter em conta o regime e a distribuição dos ventos, relevo, condições climáticas, linhas de distribuição etc.

\subsection{Análise e Viabilidade}

\subsubsection{Energia Eólica}

Os regimes de ventos, tão importantes na instalação das usinas, são resultantes de sobreposição de mecanismos atmosféricos globais e regionais. No que se refere aos regimes globais, predomina no Estado a influência de dois mecanismos: ao sul, o Anticiclone Subtropical do Atlântico, influenciado pela dinâmica intermitente das ondas de massas polares, e, ao norte, os ventos alísios, caracterizados por um regime constante. A direção desses mecanismos converge, resultando em ventos predominantes vindos de nordeste, leste e sudeste (BAHIA, 2016).

Por ter uma grande extensão territorial, a Bahia alterna diversos tipos de mecanismos regionais, principalmente brisas marinhas/terrestres e brisas montanha/vale. Em relação à sazonalidade, todo o Estado apresenta melhores índices de ventos no segundo semestre, durante o inverno e a primavera, conforme tabela 1.

Ao analisar a tabela acima, pode-se perceber que o potencial eólico estimado para todo o estado da Bahia, levando-se em consideração os resultados de integração cumulativa, com turbinas localizadas somente a 80 metros de altura e com velocidade média dos ventos iguais ou superiores a $7,0 \mathrm{~m} / \mathrm{s}$, teria uma produção total de aproximadamente $150 \mathrm{TWh} / \mathrm{ano}$. Como forma de referência, toda a matriz energética brasileira totaliza, atualmente, aproximadamente $148 \mathrm{GW}$ de potência instalada (ANEEL, 2016), tendo gerado aproximadamente 590 TWh em 2014 (EPE, 2015).

Ressalta-se que se considerou, para efeito da comparação, uma velocidade dos ventos maior ou igual a $7,0 \mathrm{~m} / \mathrm{s}$, devido ao fato de este valor se localizar dentro dos limiares mínimos de atratividade para investimentos em geração eólica, os quais, segundo o Atlas Eólico da Bahia
(COELBA, 2013), dependem dos contextos econômicos e institucionais de cada país, mas que variam, em termos de velocidades médias anuais, entre 5,5 e $7,0 \mathrm{~m} / \mathrm{s}$. Uma outra variável considerada na adoção de velocidade dos ventos maior ou igual a $7,0 \mathrm{~m} / \mathrm{s}$ foi a busca por um valor de TWh/ano intermediário, de modo que se evitasse um possível superdimensionamento, como é observado na tabela acima mencionada.

Ao contrário do restante do Nordeste, onde os ventos são melhores no litoral, na Bahia, a melhor capacidade de vento fica localizada no interior, principalmente em áreas de serras e chapadas. Uma prova do enorme potencial do centro-oeste baiano para a geração de energia elétrica por meio da utilização de usinas eólicas é justamente 0 fato de grande parte dos empreendimentos em operação, fase de construção ou com construção ainda não iniciada, situar-se nessa região do estado, a exemplo dos municípios de Caetité e Morro do Chapéu, o que ajudará, possivelmente, a tornar a Bahia a maior produtora de energia eólica do país.

Apesar da dificuldade logística de instalação dos parques eólicos nessa região específica do estado, os investimentos continuam a acontecer, - que, por si só, comprova a viabilidade dos projetos. Barifouse e Schreiber (2015) ainda atentam para o fato de o vento na região ser unidirecional, estável e sem rajadas, o que significa que a energia é produzida o tempo todo.

Tomando como base informações obtidas (em 10/09/2016) através do Portal Brasil (2016b), é possível realizar estimativa simples de quantas residências, no território baiano, são passíveis de ser abastecidas por meio de energia elétrica, gerada e distribuída a partir de parques eólicos instalados ou em processo de instalação ou com construção ainda não iniciada, mas já aprovada. Considerando-se que, na referida data acima mencionada, foi registrado valor recorde de 5.783 MW médio de geração eólica total em um único dia no Sistema Interligado Nacional - SIN (o que representou geração de $138.792 \mathrm{MW}$ no dia), e que este total produzido seria suficiente para abastecer aproximadamente 27 milhões de unidades consumidoras residenciais durante um dia inteiro, no Brasil, já que consumo diário médio residencial brasileiro está na faixa de $5,13 \mathrm{kWh}$ (PORTAL BRASIL, 2016b), o seguinte cálculo foi aplicado: 
$5.783 \mathrm{MW}-27.000 .000^{*}$ de unidades consumidoras residenciais (aproximadamente);

$5.360 \mathrm{MW}^{* *}-\mathrm{X}$ unidades consumidoras residenciais;

Aplicando-se regra de três:

$X=25.000 .000$ de unidades consumidoras residenciais (aproximadamente).

*Este resultado foi obtido através do seguinte cálculo: [5783000 KW (para que esteja na mesma unidade de medida do consumo) X 24 ( $\mathrm{n}^{\circ}$ - de horas do dia)]/5,13 KWh (consumo médio por residência no país).

** Soma de potência relacionada aos parques eólicos instalados, em processo de instalação ou com construção ainda não iniciada no território baiano, conforme dados do Banco de Informações de Geração (BIG) da ANEEL (2016).

Ou seja, a soma da potência relacionada aos parques eólicos instalados, em processo de instalação ou com construção ainda não iniciada no território baiano, possui capacidade de abastecimento de aproximadamente 25 milhões de residências durante um dia inteiro, o que representa cerca de $40 \%$ dos domicílios brasileiros, que chegaram a 62,8 milhões no ano de 2012, conforme Pesquisa Nacional por Amostra de Domicílios (IBGE, 2012).

Porém, deve ser ressaltado que este é um cálculo comparativo, realizado superficialmente como forma de demonstração do grande potencial energético para o estado da Bahia, mas que não leva em conta todas as variáveis passíveis de serem consideradas para uma melhor precisão, como, por exemplo, possíveis perdas nas linhas de transmissão, além, é claro, da eficiência de conversão da energia nos aerogeradores e da intermitência dos ventos, fatores que reduzirão consideravelmente a quantidade real de geração, como também a necessidade de manutenção constante da quantidade de MW médio de geração eólica informada acima.

Ademais, e tomando-se como base informação disponibilizada acima, de que o consumo diário médio por residência brasileira está na faixa de $5,13 \mathrm{kWh}$ (PORTAL BRASIL, 2016b) e que 0 resultado de integração cumulativa com turbinas localizadas a somente 80 metros de altura e velocidade média dos ventos iguais ou superiores a $7,0 \mathrm{~m} / \mathrm{s}$ produz um total de 150,4 TWh/ano (Tabela 1), é possível se fazer uma estimativa simples de quantas unidades residenciais poderiam ser abastecidas, durante $\mathrm{o}$ ano todo, por tal fonte, conforme pode ser demonstrado pelo seguinte cálculo:

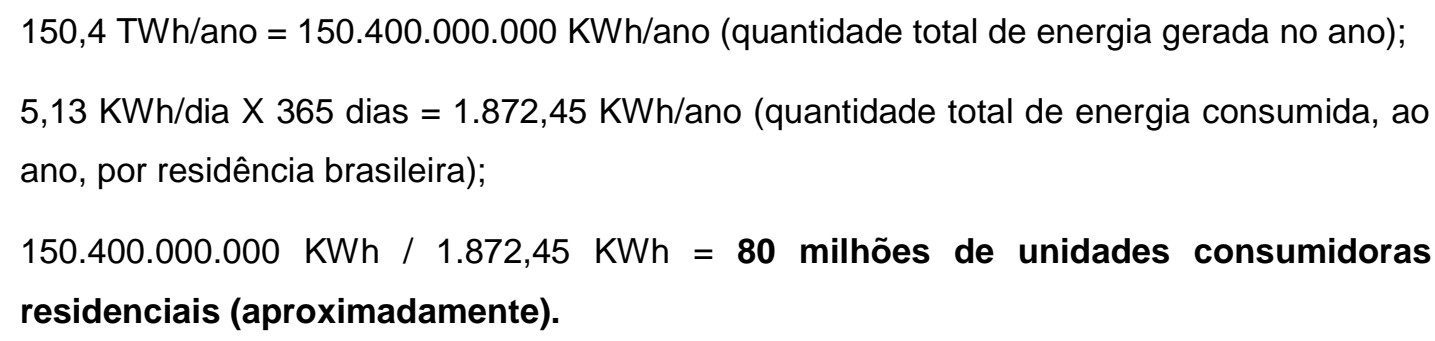

\subsubsection{Energia Solar Fotovoltaica}

Assim como ocorre em grande parte do território brasileiro, na Bahia, o potencial de utilização da energia solar é promissor na maioria de seu território, em decorrência do clima tropical e da elevada intensidade de radiação solar recebida, conforme pode ser visualizado na
Figura 5. De acordo com Imperial e Pereira (2014), o Estado possui os maiores índices de radiação solar no plano inclinado do país. No litoral e no recôncavo, os índices são medianos (cerca de $5,5 \mathrm{kWh} / \mathrm{m}^{2}$ ), mas os maiores resultados estão concentrados na região centrooeste (média anual máxima de $6,1 \mathrm{kWh} / \mathrm{m}^{2}$ ). 
Tabela 1: Estimativa do potencial de geração eólio-elétrico na Bahia

\begin{tabular}{|c|c|c|c|c|c|c|}
\hline \multicolumn{7}{|c|}{ Potencial de geração eólica solo firme (onshore) } \\
\hline \multicolumn{4}{|c|}{ Integração por faixas de velocidade } & \multicolumn{3}{|c|}{ Integração cumulativa } \\
\hline Altura (m) & Vento $(\mathrm{m} / \mathrm{s})$ & $\begin{array}{c}\text { Potência } \\
\text { instalável (GW) }\end{array}$ & $\begin{array}{c}\text { Energia } \\
\text { atual (TWh) }\end{array}$ & Vento $(\mathrm{m} / \mathrm{s})$ & $\begin{array}{c}\text { Potência } \\
\text { instalável (GW) }\end{array}$ & $\begin{array}{c}\text { Energia } \\
\text { atual (TWh) }\end{array}$ \\
\hline \multirow{8}{*}{150} & $6,0-6,5$ & 198,1 & 550,1 & $\geq 6,0$ & 566,5 & 1884,8 \\
\hline & $6,5-7,0$ & 173,2 & 568,2 & $\geq 6,5$ & 368,4 & 1334,7 \\
\hline & $7,0-7,5$ & 113,3 & 421,1 & $\geq 7,0$ & 195,2 & 766,5 \\
\hline & $7,5-8,0$ & 49,1 & 203,9 & $\geq 7,5$ & 82,0 & 345,4 \\
\hline & $8,0-8,5$ & 19,3 & 80,0 & $\geq 8,0$ & 32,9 & 141,5 \\
\hline & $8,5-9,0$ & 8,8 & 38,9 & $\geq 8,5$ & 13,6 & 61,5 \\
\hline & $9,0-9,5$ & 3,3 & 14,8 & $\geq 9,0$ & 4,8 & 21,6 \\
\hline & $\geq 9,5$ & 1,5 & 6,9 & $\geq 9,5$ & 1,5 & 6,9 \\
\hline \multirow{8}{*}{120} & $6,0-6,5$ & 171,8 & 480,4 & $\geq 6,0$ & 442,7 & 1436,4 \\
\hline & $6,5-7,0$ & 155,7 & 506,5 & $\geq 6,5$ & 270,9 & 956,0 \\
\hline & $7,0-7,5$ & 70,8 & 262,9 & $\geq 7,0$ & 115,2 & 449,6 \\
\hline & $7,5-8,0$ & 26,0 & 108,0 & $\geq 7,5$ & 44,4 & 186,7 \\
\hline & $8,0-8,5$ & 11,8 & 48,9 & $\geq 8,0$ & 18,4 & 78,7 \\
\hline & $8,5-9,0$ & 4,5 & 20,3 & $\geq 8,5$ & 6,6 & 29,8 \\
\hline & $9,0-9,5$ & 1,4 & 6,3 & $\geq 9,0$ & 2,1 & 9,6 \\
\hline & $\geq 9,5$ & 0,7 & 3,2 & $\geq 9,5$ & 0,7 & 3,2 \\
\hline \multirow{8}{*}{100} & $6,0-6,5$ & 181,6 & 507,7 & $\geq 6,0$ & 364,7 & 1147,2 \\
\hline & $6,5-7,0$ & 112,9 & 366,0 & $\geq 6,5$ & 183,1 & 639,5 \\
\hline & $7,0-7,5$ & 42,4 & 157,2 & $\geq 7,0$ & 70,1 & 273,5 \\
\hline & $7,5-8,0$ & 16,9 & 70,6 & $\geq 7,5$ & 27,7 & 116,3 \\
\hline & $8,0-8,5$ & 7,2 & 29,7 & $\geq 8,0$ & 10,8 & 45,7 \\
\hline & $8,5-9,0$ & 2,4 & 10,7 & $\geq 8,5$ & 3,6 & 16,1 \\
\hline & $9,0-9,5$ & 0,9 & 3,9 & $\geq 9,0$ & 1,2 & 5,4 \\
\hline & $\geq 9,5$ & 0,3 & 1,4 & $\geq 9,5$ & 0,3 & 1,4 \\
\hline \multirow{8}{*}{80} & $6,0-6,5$ & 156,4 & 431,0 & $\geq 6,0$ & 261,1 & 794,0 \\
\hline & $6,5-7,0$ & 66,1 & 212,6 & $\geq 6,5$ & 104,7 & 363,0 \\
\hline & $7,0-7,5$ & 23,1 & 85,7 & $\geq 7,0$ & 38,6 & 150,4 \\
\hline & $7,5-8,0$ & 9,8 & 40,6 & $\geq 7,5$ & 15,5 & 64,7 \\
\hline & $8,0-8,5$ & 3,8 & 15,8 & $\geq 8,0$ & 5,7 & 24,1 \\
\hline & $8,5-9,0$ & 1,3 & 5,5 & $\geq 8,5$ & 1,9 & 8,3 \\
\hline & $9,0-9,5$ & 0,5 & 2,2 & $\geq 9,0$ & 0,6 & 2,8 \\
\hline & $\geq 9,5$ & 0,1 & 0,6 & $\geq 9,5$ & 0,1 & 0,6 \\
\hline
\end{tabular}

Fonte: Adaptada de Camargo Schubert (2013). 


\section{Figura 5: Áreas promissoras para instalação de usinas fotovoltaicas na Bahia}

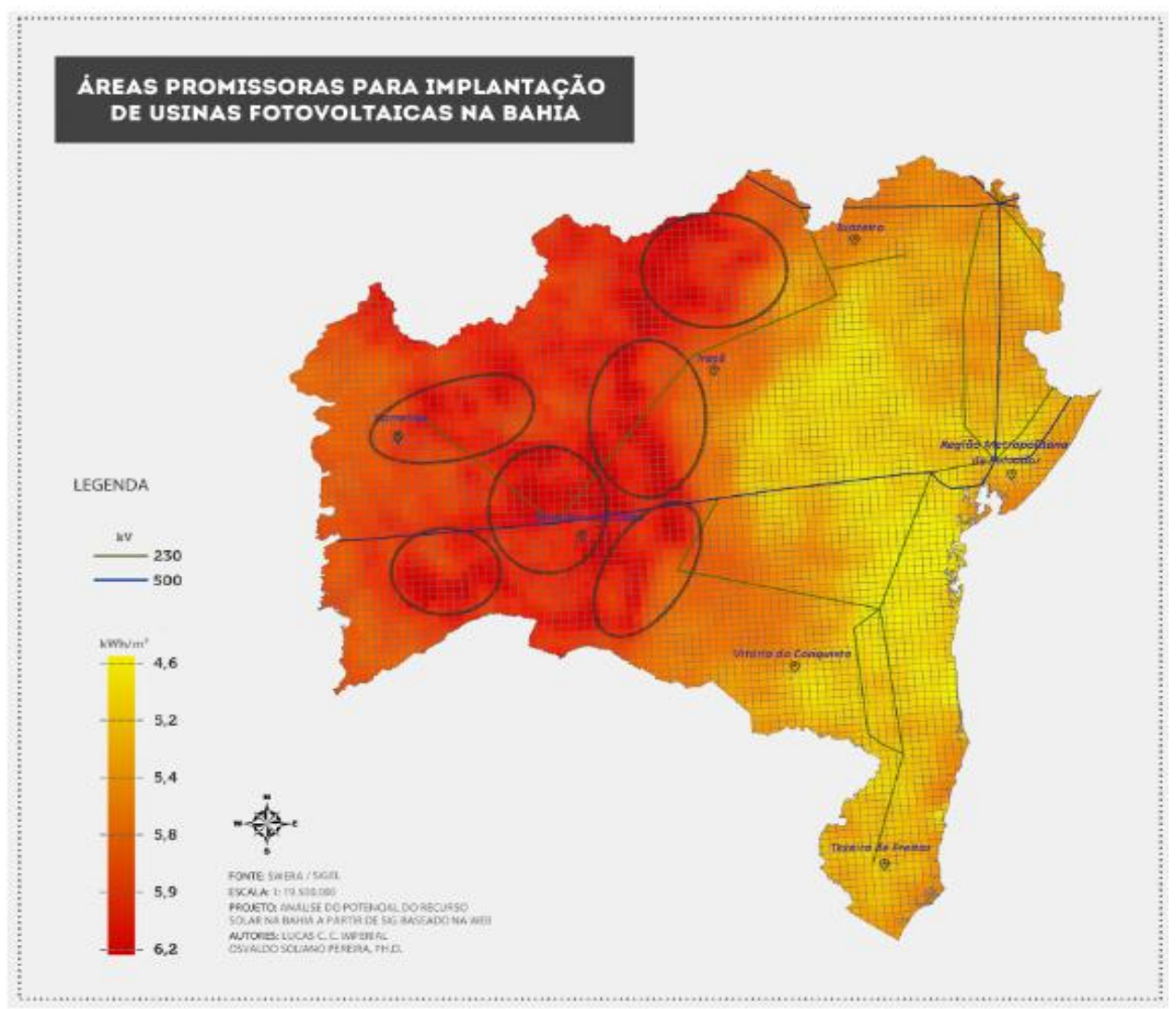

Fonte: Imperial e Pereira (2014).

Estes números podem ser considerados animadores, visto que o menor índice de radiação global brasileiro é superior aos valores encontrados em todas as partes do continente Europeu, região na qual a energia solar fotovoltaica ocupa uma boa parte da matriz energética (IMPERIAL; PEREIRA, 2014). Ainda de acordo com os mesmos autores e tomando como referência dados da BSW Solar de 2013, na Alemanha, por exemplo, país que mais utiliza a energia fotovoltaica no mundo, a capacidade instalada gira em torno de $32,4 \mathrm{GW}$, porém, com níveis de radiação solar variando entre 0,9 e 1,25 $\mathrm{kWh} / \mathrm{m}^{2}$.

De acordo com informações contidas no Atlas Solarimétrico do Brasil (2000), uma das publicações de referência a respeito da energia solar fotovoltaica no país, os valores encontrados na Região Nordeste são comparáveis a uma das melhores regiões do mundo (Dongola, no Sudão) quando se fala de índice de radiação solar disponível, conforme Tabela 2.

Outra informação contida no Atlas Solarimétrico do Brasil mostra que as variações sazonais encontradas na Região Nordeste do Brasil, por exemplo, no município baiano de Bom Jesus da Lapa, são menores que aquelas observadas em Dongola (Sudão) e Dagget (EUA), - que, consequentemente, pode resultar em importantes vantagens técnicas e econômicas para os sistemas solares potenciais a serem instalados.

Apesar do percentual de participação da energia solar fotovoltaica ainda ser irrisório perante as demais fontes presentes na matriz energética nacional, segundo o Portal Brasil (2016a), estima-se que, em 2018, o Brasil deverá entrar na lista dos 20 países com maior geração usando energia solar, considerando-se a potência já contratada e a escala de expansão dos outros países.

Continuando a análise específica do enorme potencial de aproveitamento solar na Bahia por meio da geração de energia através de painéis solares fotovoltaicos, a implantação do futuro Parque Solar Ituverava, localizado no município de Tabocas do Brejo Velho, será um dos maiores complexos solares da América Latina, com 
capacidade de $254 \mathrm{MW}$ e produção anual de energia esperada de $550 \mathrm{GWh}$. Tal parque ficará somente atrás da planta Nova Olinda, na cidade de Ribeira do Piauí (PI), que terá capacidade total de $292 \mathrm{MW}$, podendo gerar mais de $600 \mathrm{GWh}$ por ano e, assim, atender as necessidades de consumo de cerca de 300 mil lares brasileiros (GALDINO, 2016). No Complexo de Ituverava, onde serão instaladas aproximadamente 20 mil placas solares fotovoltaicas, a geração de energia elétrica poderá ser superior a $550 \mathrm{GWh}$ por ano, suficiente para atender a demanda de consumo de energia atual de mais de 268 mil domicílios brasileiros, além de evitar a emissão de mais de 185.000 toneladas de $\mathrm{CO}_{2}$ por ano (PEREIRA, 2016).

Tabela 2: Dados de radiação solar para algumas localidades do mundo

\begin{tabular}{|c|c|c|c|c|c|}
\hline Localidade & Latitude & $\begin{array}{l}\text { Hh(mínimo) } \\
\left(\mathrm{MJ} / \mathrm{m}^{2}\right)\end{array}$ & $\begin{array}{l}H_{h(\text { máximo })} \\
\left(\mathrm{MJ} / \mathrm{m}^{2}\right)\end{array}$ & $\begin{array}{l}\text { Hh(anual) } \\
\left(\mathrm{MJ} / \mathrm{m}^{2}\right)\end{array}$ & $\begin{array}{l}\mathrm{H}_{\mathrm{h}(\text { máx })} / \\
\mathrm{H}_{\mathrm{h}(\min )}\end{array}$ \\
\hline Dongola-Sudão & $19^{\circ} 10^{\prime}$ & 19,1 (Dez) & 27,7 (Mai) & 23,8 & 1,4 \\
\hline Dagget- USA & $34^{\circ} 52^{\prime}$ & $7,8(\mathrm{Dez})$ & 31,3 (Jun) & 20,9 & 4,0 \\
\hline Belém/Pará - BR & $1^{\circ} 27^{\prime}$ & 14,2 (Fev) & 19,9 (Ago) & 17,5 & 1,4 \\
\hline Floriano/PI - BR & $6^{\circ} 46^{\prime}$ & 17,0 (Fev) & 22,5 (Set) & 19,7 & 1,3 \\
\hline Petrolina/PE - BR & $9^{\circ} 23^{\prime}$ & 16,2 (Jun) & 22,7 (Out) & 19,7 & 1,4 \\
\hline $\begin{array}{l}\text { B. Jesus da Lapa/BA - } \\
\text { BR }\end{array}$ & $13^{\circ} 15^{\prime}$ & 15,9 (Jun) & 21,1 (Out) & 19,7 & 1,3 \\
\hline Cuiabá/MT - BR & $15^{\circ} 33^{\prime}$ & 14,7 (Jun) & 20,2 (Out) & 18,0 & 1,4 \\
\hline B. Horizonte/MG -BR & $19^{\circ} 56^{\prime}$ & 13,8 (Jun) & 18,6 (Out) & 16,4 & 1,3 \\
\hline Curitiba/PR - BR & $25^{\circ} 26^{\prime}$ & 9,7 (Jun) & 19,4 (Jan) & 14,2 & 2,0 \\
\hline P. Alegre/RS - BR & $30^{\circ} 1^{\prime}$ & 8,3 (Jun) & 22,1 (Dez) & 15,0 & 2,7 \\
\hline
\end{tabular}

Fonte: Adaptada de Atlas Solarimétrico do Brasil (2000).

$\mathrm{Na}$ Bahia, os municípios de Tabocas do Brejo Velho, Caetité, Bom Jesus da Lapa e Juazeiro são aqueles que concentram, até 0 momento, os investimentos direcionados à construção de usinas solares em seus territórios (ANEEL, 2016).

Além disso, os cidadãos baianos que optarem pelo sistema de mini ou microgeração de energia pode investir na geração de até $75 \mathrm{KW}$ por meio de painéis solares fotovoltaicos destinados ao abastecimento residencial, os quais terão garantia de isenção do imposto ICMS, favorecendo ainda mais o desenvolvimento desta fonte de geração de energia elétrica no Estado (BAHIA, 2016).

Assim sendo, pode-se dizer que o potencial de geração de energia proveniente de luz solar, no estado da Bahia, é visivelmente promissor, porém, a falta de investimentos e de um melhor conhecimento acerca deste setor, no passado, contribuiu como empecilho para 0 desenvolvimento desta fonte de geração de energia, que, como consequência, ainda não apresenta participação significativa na composição da matriz energética estadual.
Contudo, a previsão é que os novos investimentos que despontam no território baiano venham a ter um futuro promissor, no que diz respeito à implantação e desenvolvimento de sistemas fotovoltaicos, diversificando-se a matriz atual e fornecendo fontes de energia cada vez mais sustentáveis.

\section{RESULTADOS E DISCUSSÃO}

A construção de parques eólicos e de usinas/fazendas solares demanda grandes áreas para instalação, além de promoverem demais impactos ambientais, que englobam desde a fase de preparação do terreno, passando pela construção e se mantendo durante o funcionamento pleno dos respectivos empreendimentos. Contudo, a grande maioria de tais impactos pode ser mitigada, minimizada ou considerada pouco significativa frente às consequências que acarretam, necessitando-se, contudo, que sejam sempre respeitadas as legislações vigentes aplicáveis.

Ao analisar o potencial de aproveitamento solar e eólico para geração de energia elétrica na 
matriz energética baiana, principal foco deste estudo, as seguintes observações podem ser feitas:

- $\quad \mathrm{Na}$ matriz energética baiana, assim como pode ser observado nacionalmente, as Centrais Geradoras Hidrelétricas (CGE), Pequenas Centrais Hidrelétricas $(\mathrm{PCH})$ e Usinas Hidrelétricas (UHE) respondem juntas por grande parte do percentual de energia elétrica gerada. Enquanto na Bahia este percentual é de aproximadamente $60 \%$, no Brasil, ele sobe para pouco mais de $61 \%$;

- A partir do conhecimento da distribuição dos ventos e da radiação solar em regiões do Estado, é possível observar, de forma prévia, que a Bahia possui excelentes condições climáticas para instalação de tais fontes geradoras de energia;

- As maiores intensidades de vento, assim como de radiações solares, localizam-se na região centro-oeste baiana;

- Por meio de uma simples estimativa e comparação, observa-se que, a partir da potência encontrada no Estado (já instalada, em operação ou ainda não iniciada) e que totaliza $5.360 \mathrm{MW}$, será possível abastecer cerca de 25 milhões de residências durante um dia, se mantido tal valor de MW médio de geração durante 24 horas, considerando-se $100 \%$ de eficiência da potência total, o que não é o normal neste tipo de tecnologia;

- Ao analisar estimativa a partir da tabela elaborada pela empresa Camargo Schubert (2013) e divulgada no Atlas Eólico Bahia no mesmo ano, verifica-se que o potencial eólico estimado para todo o estado da Bahia, levando-se em consideração os resultados de integração cumulativa e com turbinas localizadas somente a 80 metros de altura e velocidade média dos ventos iguais ou superiores a $7,0 \mathrm{~m} / \mathrm{s}$, pode ser de aproximadamente $150 \mathrm{TWh} / \mathrm{ano}$, produção suficiente para suprir 0 abastecimento elétrico de cerca de 80 milhões de unidades consumidoras residenciais brasileiras;

- A Bahia apresenta elevados valores de radiação solar (média de $5,5 \mathrm{kWh} / \mathrm{m}^{2}$ no litoral e recôncavo e $6,1 \mathrm{kWh} / \mathrm{m}^{2}$ na região centro-oeste), o que representa de 4 a 5 vezes mais do que o nível de radiação encontrado na Alemanha, o maior produtor europeu, que alterna entre a faixa de 0,9 e $1,25 \mathrm{kWh} / \mathrm{m}^{2}$;
- O futuro Parque Solar Ituverava (com cerca de 20 mil placas fotovoltaicas), localizado no município de Tabocas do Brejo Velho (BA), quando concluído, será um dos maiores complexos solares da América Latina, com capacidade de $254 \mathrm{MW}$ e produção anual de energia esperada de $550 \mathrm{GWh}$, o suficiente para atender a demanda de consumo de energia anual de mais de 268 mil domicílios brasileiros, principalmente no estado da Bahia;

- Os municípios de Tabocas do Brejo Velho, Caetité, Bom Jesus da Lapa e Juazeiro são aqueles que concentram, até o momento, os investimentos direcionados à construção de usinas solares fotovoltaicas na Bahia.

Por meio destas análises, pode-se perceber que o país, de fato, possui outras formas de geração de energia que possibilitam o escape da atual crise energética que ainda assombra o sistema elétrico brasileiro, fortemente dependente da energia gerada através das usinas hidrelétricas. Isso pode ser percebido pelo simples fato de que, em períodos de menor capacidade dos reservatórios das hidrelétricas, ocorrem períodos com maiores intensidades de ventos (ZEBRAL; ARÊAS; SILVA, 2012), ou seja, enquanto a geração de energia por meio da força motriz das águas é reduzida nos períodos de estiagem, haverá uma maior geração de energia por parte das turbinas eólicas, contribuindo, assim, para uma complementaridade nos sistemas elétricos de distribuição no país; assim como uma geração promissora de energia propiciada por meio de sistemas solares fotovoltaicos.

Conforme descreve Feitosa (2016), apesar de as fontes convencionais de energia apresentarem um ótimo nível competitivo, em função do conhecimento adquirido, da capacitação e da tecnologia desenvolvida ao longo dos anos, a crescente valorização da sustentabilidade alinhada ao viés econômico, somada à segurança energética em prol da independência de cada país fazem com que cada vez mais possa ser visualizado um cenário de quebra do paradigma da economia baseada no carbono e combustíveis fósseis.

Além disso, é necessária que seja feita uma pequena abordagem sobre a importante Resolução Normativa $n^{\circ} 482$, instituída pela ANEEL (em 17/04/2012), que estabelece condições gerais para o acesso de microgeração e minigeração distribuída aos sistemas de 
distribuição de energia elétrica, assim como também determina o sistema de compensação de energia elétrica, além de dar outras providências (BRASIL, 2012). Esta Resolução foi um marco, pois passou a possibilitar que o consumidor, ao instalar pequenos geradores (a exemplo de painéis solares fotovoltaicos e microturbinas eólicas) em suas residências ou demais unidades consumidoras, troque a energia com a distribuidora local, reduzindo-se, assim, o valor de suas faturas.

\section{CONCLUSÃO}

A geração de eletricidade proveniente de fontes renováveis de energia tornou-se um tema presente no cenário mundial, sendo recorrentemente abordada por países de todo o mundo. No Brasil, o cenário não é diferente, visto que o país ainda possui uma forte dependência da energia gerada por meio de grandes centrais hidrelétricas espalhadas por todo o território, havendo a necessidade latente de diversificação da matriz energética nacional, que possibilite uma maior segurança energética ao país e a sua respectiva economia.

O Brasil, no geral, possui um enorme potencial de aproveitamento para a geração de energia por meio da utilização da força dos ventos e da luz solar, e o estado da Bahia, especificamente, é uma das unidades federativas destacadas perante os atuais investimentos e realização de leilões destinados à concessão de construção tanto de parques eólicos quanto solares no país, ao passo que representará, futuramente, significativa importância na composição e diversificação da matriz energética brasileira.

Este estudo mostrou o grande potencial de aproveitamento eólico e solar da Bahia, evidenciado, principalmente, devido às condições climáticas favoráveis em seu território, sendo possível, até, de se prever que, daqui a alguns anos, o Estado poderá vir a ter, na sua matriz energética, um maior equilíbrio entre as energias hidráulica, solar e eólica, evitando possíveis crises energéticas e barateando-se, assim, 0 preço final para o consumidor. Atualmente, a realidade apresentada ainda demonstra um percentual de $60 \%$ de energia elétrica estadual gerada por meio de sistemas hidrelétricos, ao passo que o percentual de participação das fontes provenientes de energia solar é desprezível $(0,03 \%)$ e 0 de energia eólica representa aproximadamente $18 \%$.
Contudo, torna-se importante atentar que ainda existem barreiras ao desevolvimento e disseminação de tais tecnologias no estado da Bahia. Como visto ao longo do estudo, as áreas mais promissoras localizam-se na região centrooeste do Estado, na qual ainda é possível encontrar problemas relacionados à falta de linhas de transmissão, que podem acabar barrando investimentos necessários para a economia da Bahia. Uma outra dificuldade encontrada, mas atualmente reduzida para a implantação destas usinas, seria o alto valor inicial de investimento. Esse fator é decorrente, em sua grande maioria, da ausência de empresas que produzem tais tecnologias localmente e da consequente necessidade de se importar materiais/produtos.

Além dos motivos expostos acima, os impactos ambientais advindos das etapas de preparação do terreno, construção e operação dos grandes empreendimentos também devem ser considerados, apesar de serem, na maioria das vezes, mitigados e/ou minimizados perante os benefícios que a geração eólica e/ou solar trazem, e diante de outras formas de geração de energia, como as termoétricas, que emitem gases poluentes ou que necessitam de grandes áreas para os reservatórios de água, como as hidrelétricas.

Ademais, atento a algumas destas barreiras e visando ao desenvolvimento do setor, o governo brasileiro vem criando e propondo programas de incentivos, como, por exemplo, o Programa de Incentivo às Fontes Alternativas de Energia (PROINFA) e o Programa de Desenvolvimento da Geração Distribuída de Energia Elétrica (ProGD), os quais visam estimular a geração de energia a partir de placas solares dentro das unidades consumidoras, além da redução de impostos para a instalação de grandes empreendimentos, fazendo com que o Brasil esteja entre os dez países que mais investem neste setor.

No geral, chega-se à conclusão que, provavelmente, o caminho de utilização cada vez maior de energia proveniente de usinas solares e/ou éolicas continuará sendo trilhado, assim como a produção independente de energia por pequenos consumidores, nas suas residências. A preocupação ambiental tem crescido, não devendo haver espaço para processos que agridam excessivamente o meio ambiente, mas, sim, para disseminação de tecnologias mais eficientes, mais renováveis e menos emissoras de poluição. 
Como limitação encontrada neste estudo, atenta-se para 0 fato de que ainda são consideravelmente escassos documentos técnicos e científicos referentes a estudos e aplicações das energias solar e eólica no território baiano. Como recomendação para estudos futuros, sugere-se a observação em campo dos impactos ambientais passíveis de ocorrência, a análise da legislação ambiental vigente para o setor e um maior aprofundamento das questões relacionadas ao custo médio de implantação de cada tipo de usina na Bahia.

\section{REFERÊNCIAS}

ABEEólica. Boletim anual de geração eólica 2015. Disponível em: <http://www.portalabeeolica.org.br/pdfencontro/Abeeolica_BOLETIM-2015_low.pdf>. Acesso em: 02 set. 2016 .

ALDABÓ, Ricardo. Energia eólica. São Paulo: Editora Artliber, 2002.

ANEEL. Atlas de Energia Elétrica do Brasil. 3. ed. Brasília, 2008, $236 \mathrm{p}$.

Matriz de Energia Elétrica. 2016a. Disponível

em:

<http://www.aneel.gov.br/aplicacoes/capacidadebrasil/ OperacaoCapacidadeBrasil.cfm>. Acesso em: 10 out. 2016.

Disponível

Capacidade de Geração no Estado. 2016b.

<http://www.aneel.gov.br/aplicacoes/ResumoEstadual/

CapacidadeEstado.cfm?cmbEstados=BA:BAHIA $>$.

Acesso em: 10 out. 2016.

ASSOCIAÇÃO BRASILEIRA DE NORMAS TÉCNICAS. NBR 11704: Sistemas fotovoltaicos - Classificação. Rio de Janeiro, 2008.

ATLAS SOLARIMÉTRICO DO BRASIL. Banco de Dados Solarimétricos. Chigueru Tiba et al. (Coord.). Recife: Ed. Universitária da UFPE, 2000. 111 p.: il., tab., mapas.

BAHIA. Geração de energia solar para residência está isenta de ICMS. 2016a. Disponível em: <http://www.ba.gov.br/2016/03/1713/Geracao-deenergia-solar-para-residencia-esta-isenta-deICMS.html>. Acesso em: 21 set. 2016.

Secretaria de Ciência, Tecnologia e Inovação - SECTI. Climatologia: Regimes de Vento da Bahia. 2016b. Disponível em: <http://www2.secti.ba.gov.br/atlasWEB/climatologia_p2. html>. Acesso em: 11 set. 2016.

BARIFOUSE, Rafael; SCHREIBER, Mariana. Como o Nordeste virou principal pólo da energia eólica no Brasil. Disponível em: <http://www.bbc.com/portuguese/noticias/2015/11/1 51110_energia_eolica_nordeste_rb>. Acesso em: 30 set. 2016.

BRASIL. Agência Nacional de Energia Elétrica ANEEL. Resolução Normativa $n^{\circ} 482$, de 17 de abril de 2012. Estabelece as condições gerais para o acesso de microgeração e minigeração distribuída aos sistemas de distribuição de energia elétrica, o sistema de compensação de energia elétrica, e dá outras providências. Diário Oficial [da] República Federativa do Brasil de 19 de abril de 2012. Poder Executivo, Brasília, DF, 2012, Seção 1, p. 53.

Ministério de Minas e Energia - MME. Nota Técnica DEA 19/14: Inserção da Geração Fotovoltaica Distribuída no Brasil - Condicionantes e Impactos. EPE, 2014. 64 p.

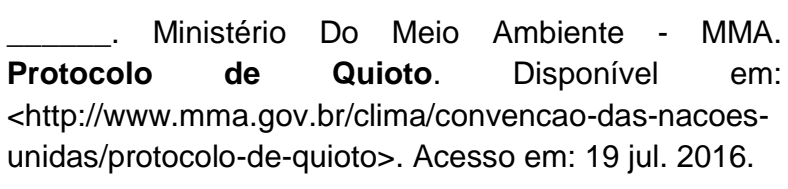

CAMARGO SCHUBERT. Atlas Eólico Bahia 2013. Curitiba, 2013. 1 atlas. Escalas variam. Disponível em: <http://www.cresesb.cepel.br/publicacoes/download/atl as_eolico/atlaseolicobahia2013.pdf>. Acesso em: 29 set. 2016.

COELBA. Estado da Bahia: Atlas do Potencial Eólico. 2013. Disponível em: http://www.cresesb.cepel.br/publicacoes/download/atlas _eolico/atlas_eolico_BA.pdf>. Acesso em: 03 set. 2016.

CRESESB. Centro de Referência para Energia Solar e Eólica Sérgio de Salvo Brito. Grupo de Trabalho de Energia Solar - GTES. Manual de Engenharia para Sistemas Fotovoltaicos. Rio de Janeiro, CRESESB, 2004.

EMPRESA DE PESQUISA ENERGÉTICA - EPE. Anuário Estatístico de Energia Elétrica, 2015. Disponível em: <http://www.epe.gov.br/AnuarioEstatisticodeEnergiaEle trica/Anu\%C3\%A1rio\%20Estat\%C3\%ADstico\%20de\%2 0Energia\%20EI\%C3\%A9trica\%202015.xIs>. Acesso em: 07 out. 2016.

EVOLUÇÃO ENERGIA EÓLICA. Energia Eólica: Aerogerador de Eixo Horizontal. Disponível em: $<$ https://evolucaoenergiaeolica.wordpress.com/aeroger ador-de-eixo-horizontal/custo-comparativo/>. Acesso em: 10 ago. 2016.

FARIAS, Leonel Marques; SELLITTO, Miguel Afonso. Uso da energia ao longo da história: evolução e perspectivas futuras. Revista Liberato, Novo Hamburgo, v. 12, n. 17, p. 01-106, jan./jun.2011. Disponível em: <http://www.liberato.com.br/sites/default/files/arquivos/ Revista_SIER/v.\%2012\%2C\%20n.\%2017\%20\%282011 \%29/1.\%20Uso\%20da\%20energia\%20ao\%20longo\%2 0da\%20hist\%F3ria.pdf>. Acesso em: 27 jul. 2016.

FEITOSA, Arnaldo. Energias renováveis: o imenso potencial brasileiro. Disponível em: 
<http://exame.abril.com.br/negocios/dino/energiasrenovaveis-o-imenso-potencial-brasileirodino89081876131/>. Acesso em: 28 set. 2016.

FILHO, Wilson Pereira Barbosa; AZEVEDO, Abílio Cesar Soares de. Impactos ambientais em usinas eólicas. In: CONGRESSO SOBRE GERAÇÃO DISTRIBUÍDA E ENERGIA NO MEIO RURAL, 8., 2013, Itajubá. Anais... Itajubá-MG: FEAM, 2013. Disponível em:

<http://www.feam.br/images/stories/arquivos/mudnacac limatica/2013/ag-267.pdf>. Acesso em: 03 ago. 2016.

GALDINO, Any Karolyne. Maior usina de energia solar da América Latina será construída em Piauí. Disponível em: <http://engenhariae.com.br/meio-ambiente/maiorusina-de-energia-solar-da-america-latina-sera-

construida-em-piaui/>. Acesso em: 10 out. 2016.

IBGE. PESQUISA NACIONAL POR AMOSTRA DE DOMICÍLIOS. 2012. Disponível em: $<\mathrm{http}$ ://www.desenvolvimento.ifal.edu.br/observatorio/in formacoes-socioeconomicas1/copy7/at_download/file>. Acesso em: 07 out. 2016.

IMPERIAL, Lucas; PEREIRA, Osvaldo Soliano. Análise do potencial do recurso solar na Bahia a partir de Software de Informação Geográfica baseado na WEB. In: CONGRESSO BRASILEIRO DE ENERGIA SOLAR, 5., 2014, Recife. Anais... Recife-PE: CBEM, 2014. Disponível em: <http://cbem.com.br/potencial-solarbahia/>. Acesso em: 10 set. 2016.

LEITE, Andréa; FALCÃO, Djalma; BORGES, Carmen. Modelagem de usinas eólicas para estudos de confiabilidade. Revista Controle \& Automação, v. 17, n. 2, 2006. Disponível em: $<$ http://www.scielo.br/scielo.php?pid=S0103-

17592006000200006\&script=sci_arttext $>$. Acesso em: 01 ago. 2016.

MIRANDA, Fábio; MACHADO, Carolina. Energia solar fotovoltaica: uma breve revisão. Revista Virtual de Química, Niterói - RJ, v. 7, n. 1, p. 126-143, 2014.

PEREIRA, Eduardo. Em 2017, o Parque Solar de Ituverava, na Bahia, gerará mais energia para o Brasil. Disponível em: <http://www.xapuri.info/meioambiente/sustentabilidade-meio-ambiente/ituveravaem-construcao-a-maior-usina-de-energia-solar-daamerica-latina/>. Acesso em: 18 out. 2016.
PORTAL BRASIL. Brasil estará entre os 20 países com maior geração solar em 2018. Portal Brasil, 2016a. Disponível em: <http://www.brasil.gov.br/infraestrutura/2016/01/brasilestara-entre-os-20-paises-com-maior-geracao-solarem-2018>. Acesso em: 13 out. 2016.

Energia eólica tem média diária recorde no Sul e Nordeste do País. Portal Brasil, 2016b. Disponível

em:<http://www.brasil.gov.br/infraestrutura/2016/09/ene rgia-eolica-tem-media-diaria-recorde-no-sul-e-nordestedo-pais>. Acesso em: 07 out. 2016.

QUAGLIA, Renato Brito. Incentivo à geração distribuída com sistemas fotovoltaicos: cenários para o setor elétrico brasileiro. 2010. 115 p. Dissertação (Pós-graduação) - Universidade Federal do ABC, Santo André, 2010.

SALINO, Pedro Jordão. Energia Eólica no Brasil: uma comparação do Proinfa e dos novos leilões. 2011. 120 f. Dissertação (Graduação) - Universidade Federal do Rio de Janeiro, Rio de Janeiro, 2011.

SANTOS, Isis Portolan dos; JUNIOR, Jair Urbanetz; RUTHER, Ricardo. Energia solar fotovoltaica como fonte complementar de energia elétrica para residências na busca da sustentabilidade. In: ENCONTRO NACIONAL DE TECNOLOGIA DO AMBIENTE CONSTRUÍDO- ENTAC, 12., 2008, Fortaleza. Anais... Fortaleza-CE: Associação Nacional de Tecnologia e Meio Ambiente Construído, 2008. Disponível em: < http://www.infohab.org.br/entac2014/2008/artigos/A161 3.pdf>. Acesso em: 15 ago. 2016.

TERCIOTE, Ricardo. A energia eólica e o meio ambiente. Campinas: UNICAMP, Faculdade de Engenharia Mecânica, 2002. Disponível em: < http://www.proceedings.scielo.br/pdf/agrener/n4v1/002. pdf $>$. Acesso em: 03 ago. 2016.

WIND ENERGY. Wind Energy The Facts. Disponível em: < http://www.wind-energy-thefacts.org/en/environment/chapter-2-environmentalimpacts/onshore-impacts.html>. Acesso em: 08 ago. 2016.

ZEBRAL, Daniel Eduardo da Silva; ABREU, Gabriel Solino de; ASSIS, Jefferson de. Energia Eólica: o uso de energias renováveis nas plataformas de petróleo. Bolsista de Valor: Revista de divulgação do Projeto Universidade Petrobras e IF Fluminense, Campos dos Goytacazes, v. 2, n. 1, p. 55-61, 201. 